\title{
Human adipose-derived stromal vascular fraction: characterization, safety and therapeutic potential in an experimental mouse model of articular injury
}

\author{
Dykstra JA ${ }^{\# 1}$, Blue ED ${ }^{\# 1}$, Negrão de Assis $\mathrm{PL}^{\# 2}$, Weimer $\mathrm{JM}^{2}$, Kota DJ ${ }^{2,3}$
}

\begin{abstract}
Due to their capacity to self-renew, proliferate and generate multi-lineage cells, adult-derived stem cells offer great potential in regenerative therapies to treat maladies such as diabetes, cardiac disease, neurological disorders and orthopedic injuries. Commonly derived from adipose tissue, the stromal vascular fraction (SVF), a heterogeneous cell population enriched with mesenchymal stem cells (MSCs), has garnered interest as a cellular therapy due to ease of accessibility as an autologous, point-of-care application. However, the heterogeneous cell population within SVF is not historically taken into consideration when injecting into patients. Here, we characterized SVF, determined its safety and verify its therapeutic effects in a NOD/scid mouse model of articular injury. SVF were isolated from lipoaspirates utilizing a commercially available system (InGeneron Inc.), while MSCs were isolated from SVF via cell culture. Flow cytometry showed that neither age nor BMI affects the frequency of progenitor cells-like $(\mathrm{CD} 31+\mathrm{CD} 34+)$, immune cells-like $(\mathrm{CD} 4+) \mathrm{T}$ cells, $(\mathrm{CD} 14+)$ monocytes and total number of cells obtained. However, there was a negative correlation between donor BMI and MSC frequency within the SVF. ELISAs showed that following LPS activation in SVF, there were low levels of TNF- $\alpha$ and high levels of IL-10 secreted. However, T cell activation with anti-CD3 or anti$\mathrm{CD} 3+$ anti-CD28, while leading to expected high levels of IFN- $\gamma$, did not lead to significant levels of TGF- $\beta$. PCR analysis showed no significant numbers of cells outside the joint 1-hour post injection, moreover, no engraftment or abnormal growth in other organs 60 -days post injection. Finally, both cell populations were able to ameliorate disease progression, as confirmed by the increase in movement of treated groups compared to injured groups. Noteworthy, the histological analysis indicated that there was no cartilage growth, suggesting an alternative therapeutic mechanism to cartilage regeneration.
\end{abstract}

Key Words: Mesenchymal stem cell; Autologous stem cells; Adipose; Cartilage

\section{Introduction}

The safety and regenerative capacity of so-called "adult stem cells" has been the source of much discussion in the scientific community. Recent findings indicate that adipose tissue, more specifically its stromal vascular fraction (SVF) component, is a rich and accessible source of cells for regenerative medicine therapeutic approaches by means of paracrine factors ${ }^{[1]}$, the existence of progenitor cells $\mathrm{s}^{[2]}$ and more notably, the isolation of a subset of cells named adipose stem/stromal cells (ASCs) $)^{[3]}$. To date, it has not been fully elucidated whether ASCs or mesenchymal stem/stromal cells (MSCs) from other tissues share the same therapeutic potential. Comparison between MSCs and ASCs remains a controversial topic ${ }^{[4-7]}$. Nevertheless, this subset of cells and their therapeutic properties are currently being investigated in hundreds of clinical trials, according to clinicaltrials.gov. The mechanism proposed in the majority of these clinical studies is the paracrine effect, rather than the differentiation paradigm ${ }^{[5-7]}$.

However, SVF therapy presents many unmet challenges. Unlike MSCs or ASCs, SVF contains a more heterogeneous cell population that includes endothelial, pericytic, progenitor and hematopoietic cells ${ }^{[8]}$, all of which perform distinct biological functions. This heterogeneity not only creates barriers for allogeneic transplantations, but more importantly, compels further studies characterizing its composition, distribution following transplant, and more critically, mechanism(s) of action. Without such studies, the safety and efficacy of SVF for clinical applications is unclear. Moreover, while SVF use continues to increase throughout the world, it is unlikely that the scientific community will resolve conflicting terms, rationales for treatments, or achieve successful, reproducible therapies until the appropriate studies are performed.

In this study, the effects of different human characteristics on the composition of SVF, the temporal-spatial distribution of SVF following normal and injured conditions and its therapeutic potential were investigated using a commercially available system for the isolation of SVF from lipoaspirates (InGeneron Inc.) and the $\mathrm{NOD} / \mathrm{scid}$ mouse as the cell recipient in a model of articular cartilage injury (one of the most common applications for $\left.\mathrm{SVF}^{[9,10]}\right)$. The hypothesis of the study was despite the existence of a heterogeneous cellular composition, SVF derived from adipose tissue exerts its therapeutic effects largely through paracrine mechanisms, without significant engraftment and differentiation. 


\section{Materials and Methods}

\section{Isolation of SVF and MSC from adipose tissue}

Adipose tissues were harvested from 49 consenting patients via lipoaspiration of the abdominal region. All human specimens were collected under the approved Sanford IRB (ID \# STUDY00000506).

SVF was aseptically isolated from adipose tissue using the Transpose ${ }^{\circledR}$ RT System (InGeneron Inc., Houston, TX). Initially, the adipose sample was mixed with Matrase $^{\mathrm{TM}}$ enzyme reagent (InGeneron Inc., Houston, TX) and pre-warmed sterile lactated ringer solution (L7501, Braun Medical, Bethlehem, PA) for an enzymatic digestion. The mixture was then processed for 30 minutes at $37^{\circ} \mathrm{C}$ in the Transpose ${ }^{\circledR}$ RT Tissue Processing Unit (InGeneron Inc., Houston, TX). The digested sample was filtered. Next, the filtered solution was washed by mixing with ringer and centrifuging for 5 minutes in the processing unit, which formed a cell pellet at the bottom of the tube. The cell pellet was collected in a syringe and the supernatant was discarded. The cell pellet was transferred back into the tube and washed two more times. After the third wash, the cell pellet was resuspended for further analysis.

Following SVF isolation, the number of nucleated cells was determined using Syto ${ }^{\mathrm{TM}} 13$ Green Fluorescent Nucleic Acid Stain (S7575, Thermo Fisher Scientific, Waltham, MA). Cell viability was determined using Trypan Blue (T8154, Sigma Aldrich Catalog, St. Louis, MO). Cells were counted manually with a hemocytometer under a microscope with a BioScope ${ }^{\mathrm{TM}}$ portable fluorescent illuminator (InGeneron Inc., Houston, TX).

MSCs were isolated through plastic adherence and characterized for the expression of CD73, CD90, CD105, CD14, CD19, CD45, HLADR, CD11b.

\section{Characterization of SVF and MSC using Flow Cytometry}

SVF samples $\left(5 \times 10^{5}\right.$ cells) were thawed at $37^{\circ} \mathrm{C}$ in a water bath and subsequently washed with $2 \mathrm{~mL}$ of Cell Staining Buffer (CSB) (420201, San Diego, CA) by gently pipetting up and down in a $15 \mathrm{~mL}$ conical tube. The cells were then centrifuged (400 g for $5 \mathrm{~min}$ ) and the supernatant removed. The cell pellet was resuspended in $1300 \mu \mathrm{L}$ of CSB and divided into $100 \mu \mathrm{L}$ aliquots in new $15 \mathrm{~mL}$ tubes (352097, Falcon, Corning, NY). Each tube received $10 \mu \mathrm{L}$ of the appropriate Fc blocker and $1 \mu \mathrm{L}$ of a 1:10,000 diluted solution of DAPI (Hoechst), except for the unstained tube. Antibodies against CD31, CD34, and CD45, all from Biolegend, were used to identify the MSC population.

Cells were incubated at $4^{\circ} \mathrm{C}$ in the dark for 20 minutes. After the incubation period, the cells were washed, centrifuged, and the supernatant aspirated. The cell pellet was resuspended in $500 \mu \mathrm{L}$ of CSB and $500 \mu \mathrm{L}$ of $4 \%$ paraformaldehyde (PFA) and incubated at room temperature (RT) in the dark for 10 minutes to allow for fixation. Following fixation, the cells were washed, centrifuged, and the supernatant discarded.

Finally, the cell pellet was resuspended in $500 \mu \mathrm{L}$ of CSB and filtered using $5 \mathrm{~mL}$ round-bottom tubes (352235, Falcon, Corning, NY). Cell populations in the SVF were analyzed using BD LSR Fortessa ${ }^{\circledR}$ (Becton Dickinson Biosciences, San Jose, CA) and FlowJo software $\mathbb{R}$ (Tree Star, Ashland, OR).

\section{SVF treatment with anti-CD3/CD-28 and LPS}

SVF isolated from patient 1039 (52 years-old female, $167.3 \mathrm{~cm}$ in height, $92.1 \mathrm{~kg}$ in weight, $35.8 \mathrm{BMI}$ ) was plated in 96 well plates $\left(5 \times 10^{4}\right.$ cells/well) and activated with lipopolysaccharide (LPS, Sigma Aldrich, St Louis, MO) or with anti-CD3/anti-CD28 coated beads (Thermo Fisher Scientific, Waltham, MA) in RPMI with heatinactivated FBS. The supernatant was collected 18 hours and 7 days post activation, respectively. TNF- $\alpha$, IL-10, IFN- $\gamma$, and TGF- $\beta$ were measured using ELISAs following the manufacturer's protocol (Biolegend).

\section{Ethics Statement}

Animal procedures (IACUC Protocol: 132-06-20D) were carried out in accordance with Sanford Research/USD Institutional Animal Care and Use Committee (USDA License 46-R-0009) approval and National Institute of Health guidelines. Forty-five mice were utilized for the articular injury model. All NOD.CB17-Prkdc scid/J (Stock No. 001303, Jackson Laboratory, Bar Harbor, ME) male mice were housed in groups of five in specific pathogen-free housing with ad libitum access to water and food and a 12-hour light-dark cycle. Some mice were moved to individual cages due to aggressive behavior.

\section{Articular Cartilage Injury Mouse Model}

To generate our articular injury models, we replicated an established protocol by Van Pham and colleagues ${ }^{[9]}$, mice were anesthetized with $3 \%$ isoflurane, followed by scrapping the knee cartilage on both hind legs using a very fine needle (32.5G). Injured animals were randomized into groups and SVF or MSCs $\left(5 \times 10^{5}\right.$ cells) were suspended in $50 \mu \mathrm{L}$ of chilled sterile $1 \mathrm{X}$ Phosphate Buffered Saline (PBS) (SH30256.01, Fisher Scientific, Chicago, IL) and injected, either intra-articularly or intravenously, 6 hours post-injury under anesthesia. The SHAM group received only PBS. Carprofen was administered as an analgesic once a day for three days after the procedure.

\section{Histology}

For histology, twenty paraffin-embedded slides per animal were prepared, all frontal sections and $5 \mu \mathrm{m}$ of thickness. Every third slice was stained with Safranin-O. Three slides per animal were imaged on a Nikon Eclipse 90i (Nikon Instruments Inc., Melville, NY) microscope using a $2 \mathrm{X}$-objective. The area of cartilage was analyzed using NIH ImageJ software (version 1.8.0, public domain). Groups were euthanized at 1,30 , and 60 days post-injury for assessment of cartilage repair. Euthanasia was performed with carbon dioxide followed by cervical dislocation.

\section{PCR analysis of engrafted cells}

Mouse organs were harvested at 1, 30, and 60 days post-injury and digested overnight for DNA isolation using a phenol/chloroform extraction. PCR amplification was performed using KM29 (forward) d(GGTTGGCCAATCTACTCCCAGG) and KM38 (reverse) d(TGGTCTCCTTAAACCTGTCTTG) primers (Takara Bio USA, Inc., Mountain View, CA) for human detection and $h / m G A P D H$ (forward) ACC ACA GTC CAT GCC ATC AC and (reverse) TCC ACC CTG TTG CTG TA (IDT Technologies, Coralville, IA). Amplification product was loaded into an agarose gel for analysis. Quantification was performed by using the PCR signal normalized to GAPDH signal by densitometry.

\section{Force Plate Actometer:}

The behavior of a cohort of animals was tested using the Force Plate Actometer (BASi, West Lafayette, IN), twice a week for four weeks starting at seven days post-injury. Animals were acclimated for 20 minutes before testing. Mice were individually placed on the 
$44 \times 44 \mathrm{~cm}$ platform of the force plate and were allowed to move freely for 20 -minute recording sessions. The data were collected on several parameters, including distance travelled, number of wall rears, number of straight runs (traveling $175 \mathrm{~mm}$ or more in 1.5 seconds), and low mobility bouts (each defined as remaining continuously in a virtual circle of $15 \mathrm{~mm}$ radius for 5 seconds).

\section{RNAScope}

To examine human mRNA transcripts in tissue samples, we used the RNAScope 2.5 HD Assay-Brown (322310, Advanced Cell Technologies, Marlborough, MA) according to the manufacturer's guidelines. Sections of $4 \mu \mathrm{m}$ of thickness were sliced from paraffinembedded lungs, brain, and joints and transferred to Superfrost Plus slides (22-037-246, Fisher Scientific, Chicago, IL). Next, tissues were prepared by fixing with $4 \%$ paraformaldehyde, cryoprotected with multiple steps of increased concentrations of sucrose, and freezing with Optimal Cutting Temperature (OCT) embedding media. Thereafter, the tissues were preheated with hydrogen peroxide and boiled for RNA retrieval. Tissues were rinsed in wash buffer between each incubation. Finally, a 3,3'-Diaminobenzidine (DAB) mixture was used for signal detection. Tissues were then counterstained with $50 \%$ hematoxylin and mounted.

\section{Statistical Analysis}

The differences between group means was analyzed using a one-way ANOVA, and a non-parametric repeated ANOVA was used to look at differences between distances traveled. Age and BMI were correlated with the number of nucleated cells using Pearson's correlation. All statistical analysis of behavioral and histological data was performed with GraphPad Prism version 5.1.1 (GraphPad Software, San Diego, CA).

\section{Results}

Neither age nor BMI correlate with number of SVF cells isolated from adipose tissue, but increased BMI correlates with diminished MSC frequency

It is known that SVF is composed of different cell types, including hematopoietic, adipose, and endothelial progenitors; as well as immune cells, fibroblasts, pericytes, endothelial cells, and other uncharacterized cells ${ }^{[8,10,11]}$. However, it is not clear how the number of nucleated cells within the SVF is affected by different parameters such as age, BMI, previous health conditions, smoking, among others. This information is critical for the establishment of dosing schemes and the amount of starting lipoaspirate material necessary for the isolation of regenerative cells. In this study, the number or frequency of cells isolated per gram of adipose tissue was correlated with both the age and BMI of each donor. The results showed that neither age nor BMI can predict the number of cells isolated per gram of adipose tissue and that the frequency of progenitor cells-like CD31+CD34+ and immune cells-like CD4+ T cells and CD14+ monocytes are likewise not significantly affected by age or BMI (Fig. 1). Interestingly, when the percentage of MSCs within SVF preparations based on nucleated CD31-CD45-CD34+ cells ${ }^{[18]}$ was investigated, there was a negative correlation between donor BMI and MSC frequency within the SVF, but not with age (Figure 1).

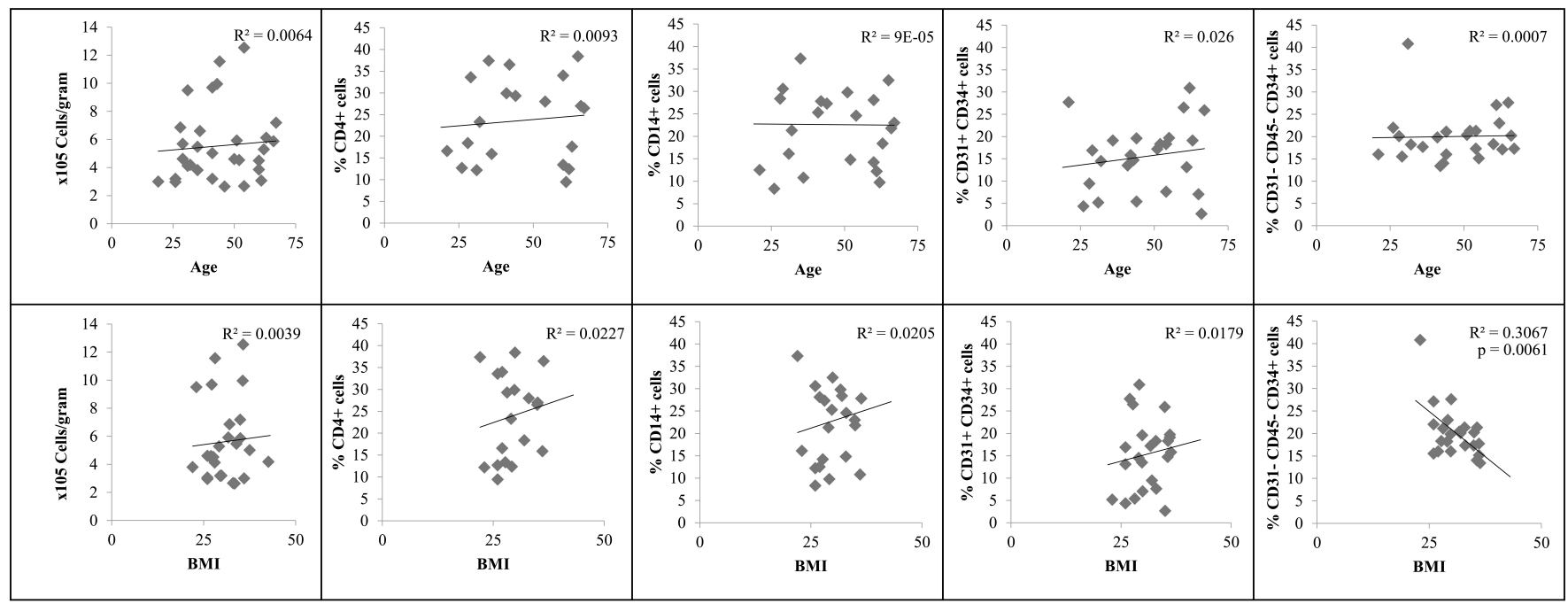

Figure 1. Number and frequency of different cell populations within the SVF. Nucleated SVF cells and SVF subpopulations (CD4+ T cells, CD14+ monocytes, CD31+CD34+ epithelial progenitors, CD31-CD45-CD34+MSCs) were plotted against donor age (Top) and BMI (Bottom) $\left(n=30\right.$, squared Pearson's correlation $\left.=R^{2}\right)$. 


\section{Activated SVF secretes high levels of IL-10, but not TGF- $\beta$}

SVF has been shown to promote angiogenesis, differentiate into adipocytes, and most notably, has exhibited anti-inflammatory effects in models of ischemic heart failure and experimental autoimmune encephalomyelitis ${ }^{[19,20]}$. However, the mechanism(s) through which SVF can inhibit inflammation, apart from having an ASC population, remains speculative. In this study, SVF cells were activated with LPS or anti-CD3 with or without anti-CD28 (Figure 2a) and the levels of both pro- (TNF- $\alpha$ and IFN- $\gamma$ ) and anti- (IL-10 and TGF- $\beta$ ) inflammatory cytokines were examined. The results showed that following LPS, there were low levels of TNF- $\alpha$ and high levels of IL10 being secreted (Figure $2 \mathrm{~b}$ ). On the other hand, T cell activation with beads coated in either anti-CD3 or anti-CD3 + anti-CD28, while leading to expected high levels of IFN- $\gamma$, did not lead to significant levels of TGF- $\beta$ (Figure 2c).

\section{SVF is confined to the lung following systemic infusion}

To determine the bio distribution of SVF following infusion, a human-specific primer was validated for the detection of SVF and MSCs. We demonstrated the specificity and detection capacity of the assay. Primer $1(\mathrm{KM})$ was shown to be specific for human cells (Figure 3a), whereas Primer 2 failed to generate a PCR product and Primer 3 and GAPDH were non-specific (Figure 3b), c. To further confirm the detection method, the knowledge that MSCs, when systemically injected, are trapped in the lungs was utilized ${ }^{[12]}$.
We also depicted the homogeneity of the MSC population when compared to the SVF (Figure 3c) and showed detection in the lung via RNAscope (Figure 3d). Hence, SVF or MSCs were infused systemically via tail injection to determine the extent to which SVF or MSCs would be retained and detected in the lung. The results indicated that both MSCs and SVF are trapped in the lung $1 \mathrm{~h}$ post injection. However, densitometry analysis showed that SVF is found in a significantly lower number $(<2$-fold) when compared to MSCs following intravenous injection (Figure $3 \mathrm{e}$ and $3 \mathrm{f}$ ). The remaining cells could not be detected anywhere else.

SVF and MSCs isolated from SVF can ameliorate articular injury without signs of engraftment and proliferation

Next, utilizing a previously described method for articular injury ${ }^{[9]}$ (Figure $4 \mathrm{a}$ and $\mathrm{b}$ ), either SVF or MSCs were delivered intraarticularly to determine the safety and therapeutic effects of these cells. As shown in figure 4c, no detectable levels of cell engraftment were observed in other organs 1-hour post injection of both cell populations, indicating injected cells do not migrate in significant numbers outside the joint. Interestingly, both cell populations were able to ameliorate disease progression, as confirmed by the increase in movement of treated groups when compared to injured groups (Figure 4d). Noteworthy, the histological analysis indicated that there was no cartilage growth (Figure 4e), suggesting an alternative therapeutic mechanism to cartilage regeneration. Finally, biodistribution analysis at 60 days post injection revealed no engraftment or abnormal growth in other organs (Figure 4f). a

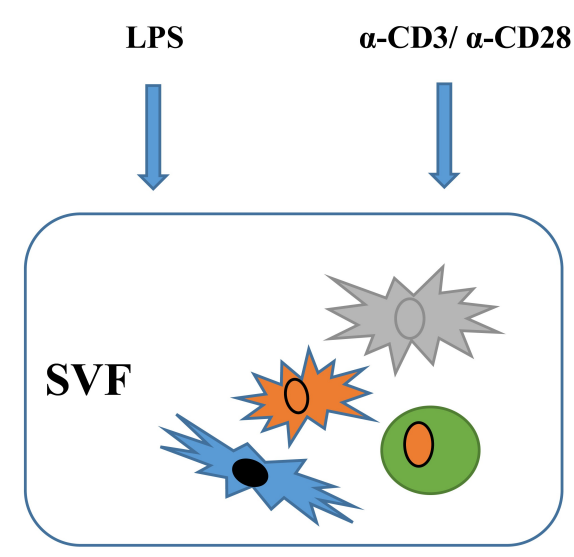

$18 \mathrm{~h}$ or $7 \mathrm{~d}$

Supernatant-ELISA b

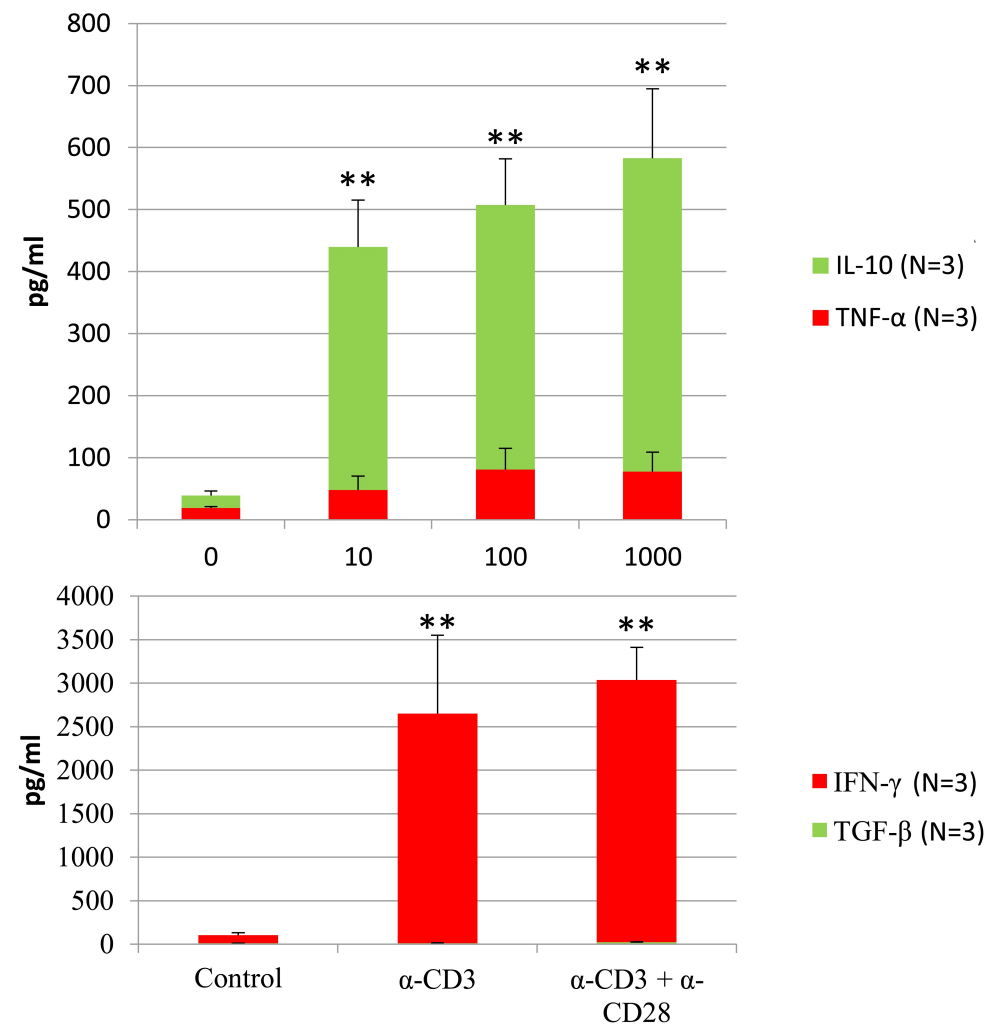

Figure 2. SVF activation. (a) SVF isolated from human adipose were activated in 96-well plates (5x10 cells/well) with LPS (100 ng/ml) or with anti-CD3/anti-CD28 coated beads and the supernatant was collected 18 hours and 7 days post activation, respectively. Levels of both pro- (TNF- $\alpha$ and IFN- $\gamma)$ and anti- (IL-10 and TGF- $\beta$ ) inflammatory cytokines were measured using ELISAs. (b) Following LPS, there were low levels of TNF- $\alpha$ and high levels of IL-10 being secreted. (c) T cell activation with beads coated in either anti-CD3 or anti-CD $3+$ anti-CD28, while leading to expected high levels of IFN- $\gamma$, did not lead to significant levels of TGF- $\beta$. (Mean \pm 3 SD, one-Way ANOVA, ** $p \leq 0.01$ compared to Control). 
a

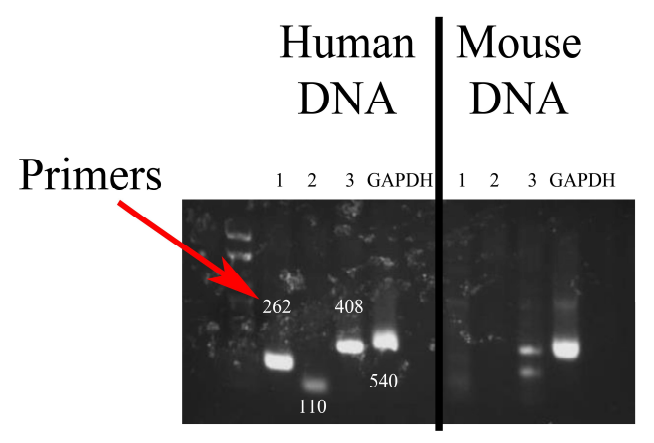

C
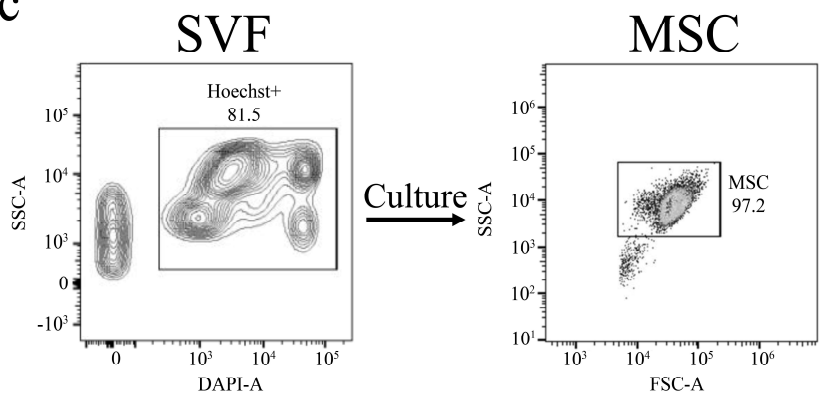

e
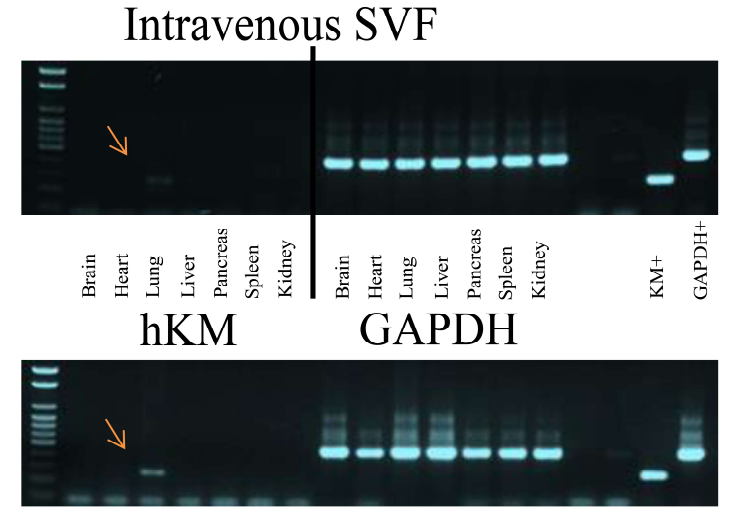

Intravenous MSC b
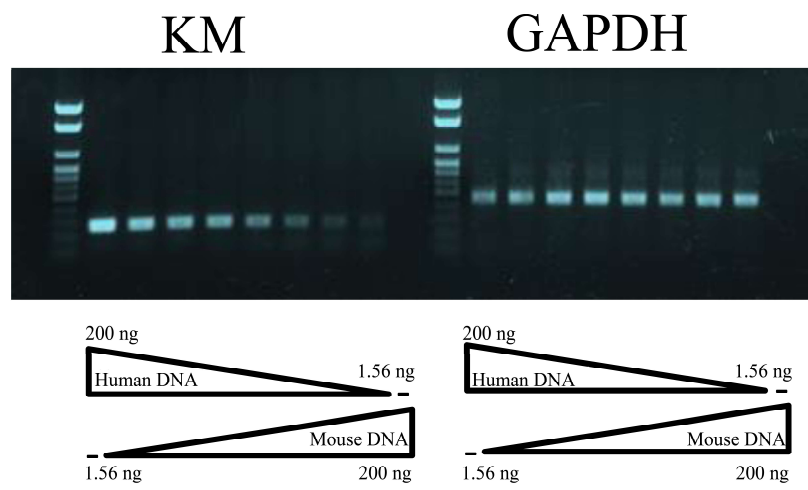

d

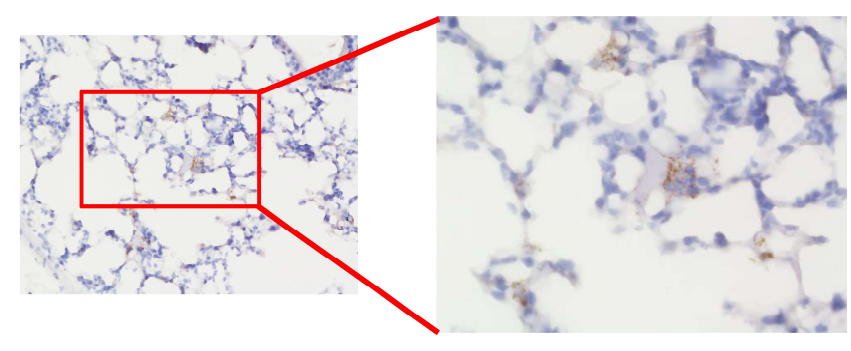

$\mathrm{f}$

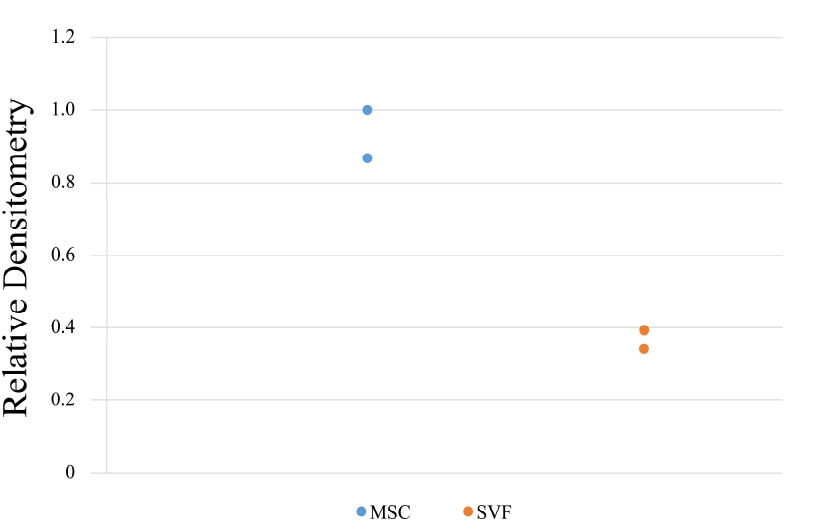

Figure 3. Biodistribution of SVF and MSC. (a) PCR of human $\beta$-globin versus mouse GAPDH-specific primers revealing Primer 1 - KM (arrow) as human-specific (b) PCR results of human and mouse DNA quantification using the human-specific primer KM and non-specific primer GAPDH. (c) Flow cytometry profile of SVF population compared to isolated MSCs. (d) MSC detection in the lung using RNAScope. (e) Representative PCR for detection of intravenously injected MSC and SVF (5x10 cells). (f) Quantification of lung engraftment (arrow) by densitometry relative to GAPDH signals $(N=2)$.

\section{Discussion}

Although the proposed use of autologous cells at point of care (treatment occurs in the same surgical procedure) minimizes potential risks associated with SVF transplants, a series of intrinsic and extrinsic risk factors still need to be considered. In particular, the presence of a heterogeneous population of cells with intrinsic progenitor potential raises concerns of unwanted tissue differentiation and neoplastic growth. Tumorous growth following transplantation of autologous stem cells from blood and olfactory mucosa has been reported in patients ${ }^{[13-15]}$. A recent systematic review of the available literature indicated the existence of a significant cancer-promoting property of ASCs ${ }^{[16]}$, although no distinction between ASCs and SVF was made. Moreover, a recent study has shown that SVF injected intradiscally in a goat model of intervertebral disc regeneration caused severe inflammation characterized by lymphocytic infiltration, neovascularization, and endplate destruction ${ }^{[17]}$, although the authors could not define the underlying destructive mechanism.

Using a commercially available device, the results of this study indicate no relationship between the number of isolated cells and the age of the donor. It is known that age deteriorates the renewal ability of progenitor cells and alters their ability to differentiate into various cell types ${ }^{[18,19]}$. Additionally, aging humans exhibit panhematopoietic decline ${ }^{[18]}$. Interestingly, this study revealed no agerelated effect on endothelial progenitor, mesenchymal stem cell, CD4+ T cells and CD14+ monocytic cell frequencies. MSCs were the only cell population that displayed a trend towards a negative correlation with patient BMI (Figure 1). A previous study has shown significant negative correlation between the number of cells obtained per milliliter of lipoaspirate with BMI, but not with age 
a

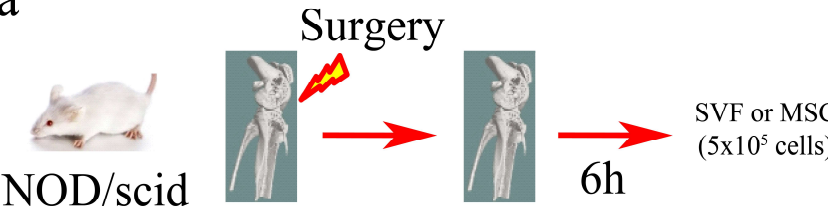

b

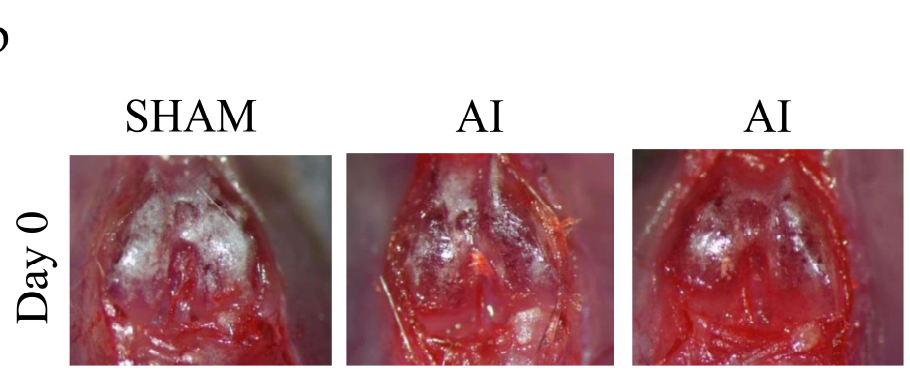

c

Determine engraftment

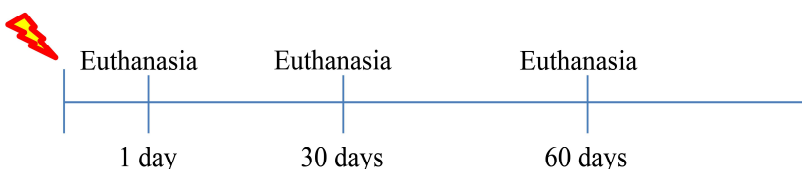

Behavior
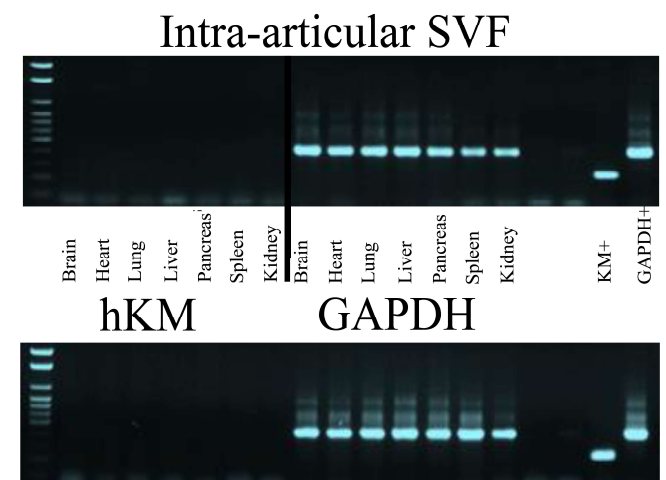

Intra-articular MSC

d

Distance Traveled

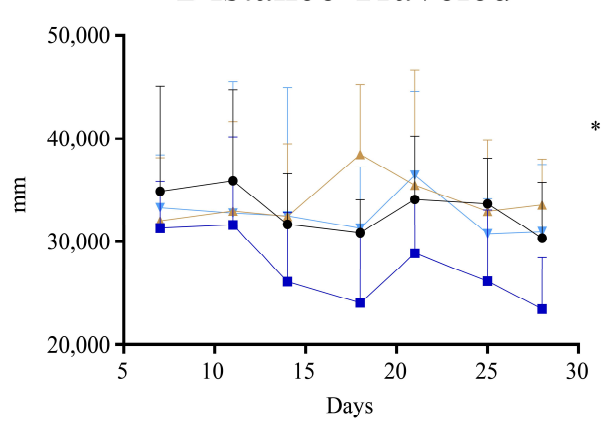

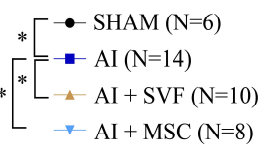

Friedman Test

(Non-parametric repeated measurement ANOVA)

e

SHAM

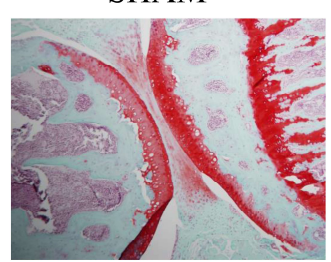

$\mathrm{AI}+\mathrm{SVF}$

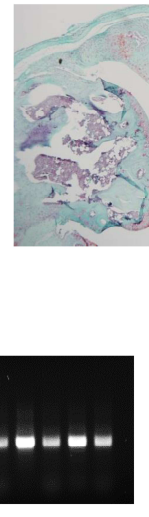

$-00000000$

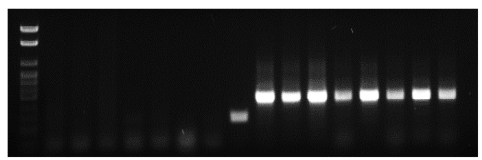

$\Lambda \mathbf{I}+\mathbf{C U T}$

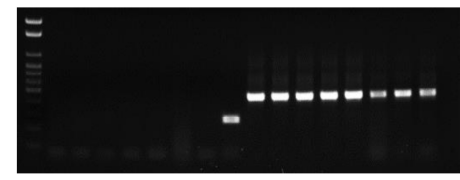

$\Lambda \mathrm{I}+\mathrm{MCC}$

Figure 4. SVF biodistribution and therapeutic outcome following articular injury. (a) Articular injury study scheme. (b) Representative pictures of injured knees. (c) No organ engraftment following intra-articular injury. (d) Distance travelled measured with force plate actimeter for sham, articular injury mice that received PBS, articular injury mice treated with SVF/MSCS. (e) Representative histological images of knee joints. (f) 60-days post-injection analysis of engraftment in various mouse organs (Mean \pm SD, Friedman Test, * $p \leq 0.05$ compared to Control). 
of the donor ${ }^{[20]}$. The current study population had a similar average age of 43.6 versus 44 years of age (Figure 1), and it was also composed in its majority by women ( 83.3 versus 87.5$)$. However, the donor population displayed a higher BMI of 31.41 versus 24.9 (Figure 1). In obese individuals, adipose tissue macrophage numbers increase and correlate with adipose tissue inflammation and insulin resistance ${ }^{[21,22]}$, which could have increased the SVF cellularity, although the $\mathrm{CD} 14+$ and $\mathrm{CD} 4+\mathrm{T}$ cell population here showed only a diminutive positive correlation (Figure 1). Another possible explanation for the difference between the studies could be attributed to the location from which the adipose cells were obtained during lipoaspiration. Subcutaneous and omental fat display opposite frequencies of mesothelial versus endothelial cells ${ }^{[23,24]}$. Along the same lines, inguinal fat pads have been shown to possess a higher composition of macrophages and monocytes than SVF derived from epididymal fat stores ${ }^{[25]}$. Interestingly, in this study MSC frequency seemed to negatively correlate with BMI (Figure 1), which aligns with the fact that during obesity, MSCs are a major source of adipocyte generation ${ }^{[26,27]}$.

Immunomodulation emerges as a therapeutic property of $\mathrm{SVF}^{[27,28]}$. However, the mechanisms through which SVF can modulate immune responses remains to be elucidated. Immune cell activation largely drives polarization of immune cells towards either a pro-inflammatory phenotype, characterized by the expression of factors such as IL-1B, TNF- $\alpha$, and IFN- $\gamma^{[29]}$, or towards an anti-inflammatory phenotype, in which factors like IL-10 and TGF- $\beta$ play a major role ${ }^{[30]}$. This study demonstrated that monocytic activation through LPS led to a significant increase in IL-10 and low levels of TNF- $\alpha$ (Figure 2b). These results strongly suggest the presence of anti-inflammatory monocytes within the SVF. Fjeldoborg and colleagues have shown that the relative expression of CD163 and IL-10 were elevated, and TNF- $\alpha$ and IL- 6 were reduced in monocytes from obese subjects ${ }^{[31]}$, while another group has described isolated monocytes from adipose tissue capable of excessive pro-inflammatory mediator production ${ }^{[32]}$. Interestingly, human adipose tissue accumulation is associated with pro-inflammatory changes in subcutaneous rather than visceral adipose tissue, which suggests that differences in lipoaspirate samples could explain such differences. On the other hand, lymphocytic activation with anti-CD3 and anti-CD28 led to high levels of IFN- $\gamma$ versus TGF- $\beta$ (Figure $2 c$ ). These results were expected since it is well known that $\mathrm{T}$ cells contribute to the early steps of adipose tissue inflammation during obesity ${ }^{[33,34]}$.

Next, using an articular injury model with NOD/scid mice, this study established a method based on human-specific primer detection for the tracking of human SVF following transplantation (Figure 3a). An obvious shortcoming of this method lies in its resolution (Figure $3 b$ ). Since each mammalian cell contains about $6 \mathrm{pg}$ of DNA, the lowest detection threshold lies in the hundreds of cells, so any engraftment levels lower than that would not be detected. As expected, SVF was found in the lung, but not significantly in other peripheral organs , shortly following systemic infusion (Figure 3e) as previously described for MSCs ${ }^{[12]}$. However, SVF was found in significantly lesser number when compared to MSCs (Figure 3f). This observation can be explained by the size of each cell population. Cultured MSCs have an average diameter of $30.4 \mu \mathrm{m}$, whereas cell components of SVF like endothelial progenitor, lymphocytes, and pre-adipocytes measure around $10 \mu \mathrm{m}^{[35]}$. Our MSCs were isolated through plastic adherence and were positive for $\mathrm{CD} 73, \mathrm{CD} 90$, while being negative for CD14, CD19, CD45, HLA-DR, CD11b and CD105 (Supplemental Figure 1).
Interestingly, our MSCs were negative for CD105. Although CD105 is generally considered an important marker for $\mathrm{MSCs}^{[36]}$ several reports have shown that its expression vary depending upon MSC source (bone marrow-, adipose tissue-, umbilical cord blood derived MSCs or placenta-derived MSCs), culture time in vitro and differentiation state [reviewed in 37]. Likewise, differentiation capacity of MSCs from different sources have demonstrated variable results. Differentiation capacities into all three lineages was demonstrated for $71.4 \%$ of bone marrow and adipose-derived MSC samples (5 of 7; 10 of 14 respectively) $)^{[38]}$. Therapeutically, injured mice treated with MSCs and SVF showed amelioration of injury despite no signs of long-term engraftment (Figure 4f), which strongly indicates the existence of a paracrine effect that could not be determined in this study. SVF has been shown to secrete various growth factors like vascular endothelial growth factor (VEGF) ${ }^{[1]}$. SVF was also shown to display anti-inflammatory effects in models of ischemic heart failure ${ }^{[39]}$ and experimental autoimmune encephalomyelitis ${ }^{[40]}$, although the mechanism(s) through which SVF can inhibit inflammation, apart from having an ASC population, remains highly speculative. Because SVF is a heterogeneous population of cells and the cross-talk effects between SVF and host tissue are largely unknown, defining the therapeutic properties of the SVF will be challenging. For MSCs, the list of paracrine effects are better described and include PGE2 in models of arthritis ${ }^{[41]}$, Tumor necrosis factor-inducible gene 6 protein (TSG-6) for diabetes ${ }^{[6]}$ and myocardial infarct ${ }^{[12]}$, Indoleamine 2,3-dioxygenase (IDO) for allograft models ${ }^{[42]}$ and are reviewed elsewhere ${ }^{[43]}$. Moreover, intraarticular infusion did not lead to cell engraftment and proliferation in peripheral organs (Figure $4 \mathrm{c}$ and $4 \mathrm{~d}$ ), supporting a safe profile for the use of SVF intra-articularly. Despite the existence of studies describing the engraftment of adipose derived mesenchymal progenitor cells in a model of $\mathrm{OA}^{[44,45]}$, the lack of engraftment of cells like MSCs are consistent in pre-clinical models aiming to resurface the degenerated cartilage ${ }^{[46}$, reviewed in 47$]$. And due to the difficulties in labeling $\mathrm{SVF}^{[45]}$, both pre-clinical and clinical studies ${ }^{[48,49]}$ lack SVF engraftment and survival data.

\section{Conclusion}

Overall, this study provides insight into the characteristics of SVF, its therapeutic properties, and validates the mouse model for articular cartilage injuries. This study also provides pre-clinical evidence for the feasibility of utilizing SVF in articular injuries in a clinical setting. However, additional studies are needed to elucidate the mechanism of action of SVF and further safety studies are necessary to determine the long-term effects of SVF injections.

\section{References}

1. Rehman J, Traktuev D, Li J, Merfeld-Clauss S, Temm-Grove CJ, Bovenkerk JE, Pell CL, Johnstone BH, Considine RV, March KL. Secretion of angiogenic and antiapoptotic factors by human adipose stromal cells. Circulation. 2004;109(10):1292-8.

2. Traktuev DO, Prater DN, Merfeld-Clauss S, Sanjeevaiah AR, Saadatzadeh MR, Murphy M, Johnstone BH, Ingram DA, March KL. Robust functional vascular network formation in vivo by cooperation of adipose progenitor and endothelial cells. Circ Res. 2009;104(12):1410-20.

3. Zuk PA, Zhu M, Mizuno H, Huang J, Futrell JW, Katz AJ, Benhaim P, Lorenz HP, Hedrick MH. Multilineage cells from human adipose tissue: implications for cell-based therapies. Tissue Eng. 2001;7(2):211-28. 
4. Strioga M, Viswanathan S, Darinskas A, Slaby O, Michalek J. Same or not the same? Comparison of adipose tissue-derived versus bone marrow-derived mesenchymal stem and stromal cells. Stem Cells Dev. 2012;21(14):2724-52.

5. Dykstra JA, Facile T, Patrick RJ, Francis KR, Milanovich S, Weimer JM, Kota DJ. Concise Review: Fat and Furious: Harnessing the Full Potential of Adipose-Derived Stromal Vascular Fraction. Stem cells translational medicine. 2017;6(4):1096-108.

6. Kota DJ, Wiggins LL, Yoon N, Lee RH. TSG-6 produced by hMSCs delays the onset of autoimmune diabetes by suppressing Th1 development and enhancing tolerogenicity. Diabetes. 2013;62(6):2048-58.

7. Prockop DJ, Kota DJ, Bazhanov N, Reger RL. Evolving paradigms for repair of tissues by adult stem/progenitor cells (MSCs). J Cell Mol Med. 2010;14(9):2190-9.

8. Bourin P, Bunnell BA, Casteilla L, Dominici M, Katz AJ, March KL, Redl H, Rubin JP, Yoshimura K, Gimble JM. Stromal cells from the adipose tissue-derived stromal vascular fraction and culture expanded adipose tissue-derived stromal/stem cells: a joint statement of the International Federation for Adipose Therapeutics and Science (IFATS) and the International Society for Cellular Therapy (ISCT). Cytotherapy. 2013;15(6):641-8.

9. Van Pham P, Hong-Thien Bui K, Quoc Ngo D, Tan Khuat L, Kim Phan N. Transplantation of Nonexpanded Adipose Stromal Vascular Fraction and Platelet-Rich Plasma for Articular Cartilage Injury Treatment in Mice Model. J Med Eng. 2013;2013:832396.

10. Gimble JM, Katz AJ, Bunnell BA. Adipose-derived stem cells for regenerative medicine. Circ Res. 2007;100(9):1249-60.

11. Gimble JM, Nuttall ME. Adipose-derived stromal/stem cells (ASC) in regenerative medicine: pharmaceutical applications. Curr Pharm Des. 2011;17(4):332-9.

12. Lee RH, Pulin AA, Seo MJ, Kota DJ, Ylostalo J, Larson BL, Semprun-Prieto L, Delafontaine P, Prockop DJ. Intravenous hMSCs improve myocardial infarction in mice because cells embolized in lung are activated to secrete the anti-inflammatory protein TSG-6. Cell Stem Cell. 2009;5(1):54-63.

13. Dlouhy BJ, Awe O, Rao RC, Kirby PA, Hitchon PW. Autograftderived spinal cord mass following olfactory mucosal cell transplantation in a spinal cord injury patient: Case report. J Neurosurg Spine. 2014;21(4):618-22.

14. Jonsson TB, Larzon T, Arfvidsson B, Tidefelt U, Axelsson CG Jurstrand M, Norgren L. Adverse events during treatment of critical limb ischemia with autologous peripheral blood mononuclear cell implant. Int Angiol. 2012;31(1):77-84.

15. Thirabanjasak D, Tantiwongse K, Thorner PS Angiomyeloproliferative lesions following autologous stem cell therapy. J Am Soc Nephrol. 2010;21(7):1218-22.

16. Freese KE, Kokai L, Edwards RP, Philips BJ, Sheikh MA, Kelley J, Comerci J, Marra KG, Rubin JP, Linkov F. Adipose-derived stems cells and their role in human cancer development, growth, progression, and metastasis: a systematic review. Cancer Res. 2015;75(7):1161-8.

17. Detiger SE, Helder MN, Smit TH, Hoogendoorn RJ. Adverse effects of stromal vascular fraction during regenerative treatment of the intervertebral disc: observations in a goat model. Eur Spine J. 2015;24(9):1992-2000.

18. Henry CJ, Marusyk A, DeGregori J. Aging-associated changes in hematopoiesis and leukemogenesis: what's the connection? Aging (Albany NY). 2011;3(6):643-56.

19. Saheera S, Nair RR. Accelerated decline in cardiac stem cell efficiency in Spontaneously hypertensive rat compared to normotensive Wistar rat. PloS one. 2017;12(12):e0189129.

20. Aust L, Devlin B, Foster SJ, Halvorsen YD, Hicok K, du Laney T, Sen A, Willingmyre GD, Gimble JM. Yield of human adiposederived adult stem cells from liposuction aspirates. Cytotherapy. 2004;6(1):7-14

21. Castoldi A, Naffah de Souza C, Camara NO, Moraes-Vieira PM. The Macrophage Switch in Obesity Development. Front Immunol. $2015 ; 6: 637$.
22. Silva KR, Liechocki S, Carneiro JR, Claudio-da-Silva C, MayaMonteiro CM, Borojevic R, Baptista LS. Stromal-vascular fraction content and adipose stem cell behavior are altered in morbid obese and post bariatric surgery ex-obese women. Stem Cell Res Ther. 2015;6:72.

23. Takahashi K, Goto T, Mukai K, Sawasaki Y, Hata J. Cobblestone monolayer cells from human omental adipose tissue are possibly mesothelial, not endothelial. In Vitro Cell Dev Biol. 1989;25(2):109-11.

24. Williams SK, Wang TF, Castrillo R, Jarrell BE. Liposuctionderived human fat used for vascular graft sodding contain endothelial cells and not mesothelial cells as the major cell type. J Vasc Surg. 1994;19(5):916-23

25. Du ZY, Ma T, Lock EJ, Hao Q, Kristiansen K, Froyland L, Madsen L. Depot-dependent effects of adipose tissue explants on co-cultured hepatocytes. PloS one. 2011;6(6):e20917. Epub 2011/06/21. doi: 10.1371/journal.pone.0020917.

26. Matsushita K, Dzau VJ. Mesenchymal stem cells in obesity: insights for translational applications. Lab Invest. 2017;97(10):1158-66.

27. Guo J, Nguyen A, Banyard DA, Fadavi D, Toranto JD, Wirth GA, Paydar KZ, Evans GR, Widgerow AD. Stromal vascular fraction: A regenerative reality? Part 2: Mechanisms of regenerative action. J Plast Reconstr Aesthet Surg. 2016;69(2):180-8.

28. Bowles AC, Wise RM, Gerstein BY, Thomas RC, Ogelman R, Febbo I, Bunnell BA. Immunomodulatory Effects of Adipose Stromal Vascular Fraction Cells Promote Alternative Activation Macrophages to Repair Tissue Damage. Stem Cells. 2017;35(10):2198-207.

29. Zhang JM, An J. Cytokines, inflammation, and pain. Int Anesthesiol Clin. 2007;45(2):27-37.

30. Sanjabi S, Zenewicz LA, Kamanaka M, Flavell RA. Antiinflammatory and pro-inflammatory roles of TGF-beta, IL-10, and IL-22 in immunity and autoimmunity. Curr Opin Pharmacol. 2009;9(4):447-53

31. Fjeldborg K, Pedersen SB, Moller HJ, Christiansen T, Bennetzen M, Richelsen B. Human adipose tissue macrophages are enhanced but changed to an anti-inflammatory profile in obesity. J Immunol Res. 2014;2014:309548.

32. Zeyda M, Farmer D, Todoric J, Aszmann O, Speiser M, Gyori G, Zlabinger GJ, Stulnig TM. Human adipose tissue macrophages are of an anti-inflammatory phenotype but capable of excessive proinflammatory mediator production. Int $\mathrm{J}$ Obes (Lond). 2007;31(9):1420-8.

33. Morin SO, Poggi M, Alessi MC, Landrier JF, Nunes JA Modulation of $\mathrm{T}$ Cell Activation in Obesity. Antioxid Redox Signal. 2017;26(10):489-500.

34. Bora P, Majumdar AS. Adipose tissue-derived stromal vascular fraction in regenerative medicine: a brief review on biology and translation. Stem Cell Res Ther. 2017;8(1):145.

35. Ge J, Guo L, Wang S, Zhang Y, Cai T, Zhao RC, Wu Y. The size of mesenchymal stem cells is a significant cause of vascular obstructions and stroke. Stem Cell Rev. 2014;10(2):295-303.

36. Dominici M, Le Blanc K, Mueller I, Slaper-Cortenbach I, Marini F, Krause D, Deans R, Keating A, Prockop D, Horwitz E. Minima criteria for defining multipotent mesenchymal stromal cells. The International Society for Cellular Therapy position statement. Cytotherapy. 2006;8(4):315-7.

37. Anderson P, Carrillo-Gálvez AB, García-Pérez A, Cobo M, Martín F. CD105 (Endoglin)-Negative Murine Mesenchymal Stromal Cells Define a New Multipotent Subpopulation with Distinct Differentiation and Immunomodulatory Capacities. PloS one. 2013;8(10):e76979.

38. Kern S, Eichler H, Stoeve J, Klüter H, Bieback K. Comparative Analysis of Mesenchymal Stem Cells from Bone Marrow, Umbilical Cord Blood, or Adipose Tissue. STEM CELLS. 2006;24(5):1294-301.

39. Premaratne GU, Ma LP, Fujita M, Lin X, Bollano E, Fu M. Stromal vascular fraction transplantation as an alternative therapy for ischemic heart failure: anti-inflammatory role. Journal of cardiothoracic surgery. 2011;6:43. 
40. Semon JA, Zhang X, Pandey AC, Alandete SM, Maness C, Zhang S, Scruggs BA, Strong AL, Sharkey SA, Beuttler MM, Gimble JM, Bunnell BA. Administration of murine stromal vascular fraction ameliorates chronic experimental autoimmune encephalomyelitis. Stem cells translational medicine. 2013;2(10):789-96.

41. Kim HS, Shin TH, Lee BC, Yu KR, Seo Y, Lee S, Seo MS, Hong IS, Choi SW, Seo KW, Nunez G, Park JH, Kang KS. Human umbilical cord blood mesenchymal stem cells reduce colitis in mice by activating NOD2 signaling to COX2. Gastroenterology. 2013;145(6):1392-403.e1-8.

42. Ge W, Jiang J, Arp J, Liu W, Garcia B, Wang H. Regulatory T-cell generation and kidney allograft tolerance induced by mesenchymal stem cells associated with indoleamine 2,3-dioxygenase expression. Transplantation. 2010;90(12):1312-20.

43. Spees JL, Lee RH, Gregory CA. Mechanisms of mesenchymal stem/stromal cell function. Stem Cell Research \& Therapy. 2016;7(1):125

44. Wang W, He N, Feng C, Liu V, Zhang L, Wang F, He J, Zhu T, Wang S, Qiao W, Li S, Zhou G, Zhang L, Dai C, Cao W. Human adipose-derived mesenchymal progenitor cells engraft into rabbit articular cartilage. Int J Mol Sci. 2015;16(6):12076-91

\section{Abbreviations}

\begin{tabular}{|c|c|}
\hline AI & : Articular Injury \\
\hline ANOVA & : Analysis of Variance \\
\hline ASCs & : Adipose Stem/Stromal Cells \\
\hline BMI & : Body Mass Index \\
\hline CD & : Cluster of Differentiation \\
\hline CSB & : Cell Staining Buffer \\
\hline DAB & : 3,3'-Diaminobenzidine \\
\hline ELISA & : Enzyme-Linked Immunosorbent Assay. \\
\hline FBS. & : Fetal Bovine Serum \\
\hline IACUC & : Institutional Animal Care and Use Committee \\
\hline IFN & : Interferons \\
\hline IL & : Interleukin \\
\hline IN & : Intranasal \\
\hline IRB & : Institutional Review Board \\
\hline IV & : Intravenous \\
\hline LPS & : Lipopolysaccharides \\
\hline MSCs & : Mesenchymal Stem Cells \\
\hline NOD & : Non-Obese Diabetic \\
\hline OCT & : Optimal Cutting Temperature \\
\hline PBS & : Phosphate Buffered Saline \\
\hline PCR & : Polymerase Chain Reaction \\
\hline PFA & : Paraformaldehyde \\
\hline Prkdc & : Protein Kinase, DNA-Activated, Catalytic Subunit \\
\hline RPMI & : Roswell Park Memorial Institute (Media) \\
\hline scid & : Severe Combined Immune Deficiency \\
\hline SVF & : Stromal Vascular Fraction \\
\hline TGF- $\beta$ & : Transforming Growth Factor \\
\hline TNF- $\alpha$ & : Tumor Necrosis Factor \\
\hline USDA & : United States Department of Agriculture \\
\hline
\end{tabular}

45. Lv X, He J, Zhang X, Luo X, He N, Sun Z, Xia H, Liu V, Zhang L, Lin X, Lin L, Yin H, Jiang D, Cao W, Wang R, Zhou G, Wang W. Comparative Efficacy of Autologous Stromal Vascular Fraction and Autologous Adipose-Derived Mesenchymal Stem Cells Combined With Hyaluronic Acid for the Treatment of Sheep Osteoarthritis. Cell transplantation. 2018;27(7):1111-25.

46. Murphy JM, Fink DJ, Hunziker EB, Barry FP. Stem cell therapy in a caprine model of osteoarthritis. Arthritis and rheumatism 2003;48(12):3464-74.

47. Barry F, Murphy M. Mesenchymal stem cells in joint disease and repair. Nature reviews Rheumatology. 2013;9(10):584-94.

48. Bansal H, Comella K, Leon J, Verma P, Agrawal D, Koka P, Ichim T. Intra-articular injection in the knee of adipose derived stromal cells (stromal vascular fraction) and platelet rich plasma for osteoarthritis. J Transl Med. 2017;15(1):141-

49. Michalek J, Vrablikova A, Darinskas A, Lukac L, Prucha J, Skopalik J, Travnik J, Cibulka M, Dudasova Z. Stromal vascular fraction cell therapy for osteoarthritis in elderly: Multicenter casecontrol study. J Clin Orthop Trauma. 2019;10(1):76-80. 


\section{Potential Conflicts of Interests}

None

\section{Acknowledgements}

Marisela Killian, Zili Gao for assistance in the Flow Cytometry Core, Claire Evans for assistance in the Histology and Imaging Core and both at Sanford Research.

\section{Financial support}

This work was supported by a grant from the National Institutes of Health to J.M.W. (R01NS082283). This work also received support from the Histology and Imaging Core within the Sanford Research Center for Pediatric Research (NIH P20GM103620), and the Flow Cytometry Core within the Sanford Research Center for Cancer Biology (NIH P20GM103548).

\section{Corresponding Author}

Daniel Jiro Kota; 1364 Clifton Rd NE. Cellular Therapy Lab. D639. Atlanta, GA. 30322, USA; Email: djkota@emory.edu 